\title{
First record of Harpiola (Chiroptera, Vespertilionidae) from Vietnam
}

\author{
Sergei V. Kruskop, Mikhail V. Kalyakin \& Alexei V. Abramov
}

\begin{abstract}
The tube-nosed bat of the genus Harpiola was for the first time captured in Vietnam. The animal was caught into mist net in Ngoc Ling Mountains at the elevation $2250 \mathrm{~m}$. This is the first record of Harpiola from Asian mainland eastward of India. Comparison of external characters, dental features and measurements with published data reveal considerable similarity between Vietnamese specimen and $H$. isodon from Taiwan. Talonids of the first two lower molars of Vietnamese specimen demonstrate myotodont type of structure.
\end{abstract}

KEW WORDS: Harpiola isodon, Ngoc Linh Mountains, Vietnam, new record.

Sergei V. Kruskop [kruskop@zmmu.msu.ru], Zoological Museum, Moscow State University, ul. Bolshaya Nikitskaya 6, Moscow 125009, Russia; Mikhail V. Kalyakin [kalyakin@zmmu.msu.ru], Zoological Museum, Moscow State University, ul.Bolshaya Nikitskaya 6, Moscow 125009, Russia; Alexei V. Abramov [aav@aa2510.spb.edu],Zoological Institute, Russian Academy of Sciences, Universitetskaya nab. 1, Saint Petersburg 199034, Russia.

\section{Первая находка представителя рода Harpiola (Chiroptera, Vespertilionidae) во Вьетнаме}

\section{С.В. Крускоп, М.В. Калякин, А.В. Абрамов}

РЕЗЮМЕ. Представитель рода Harpiola был впервые обнаружен во Вьетнаме. Зверек был пойман при помощи паутинной сетки в горах Нгоклинь на высоте 2250 м. Это первая находка Harpiola из материковой части Азии восточнее Индии. Сравнение внешних черт, зубных признаков и промеров с ранее опубликованными данными показало значительное сходство между вьетнамским экземпляром и H. isodon с Тайваня. Талониды первых двух нижних моляров обсуждаемого экземпляра демонстрируют миотодонтный тип строения.

КЛЮЧЕВЫЕ СЛОВА: Harpiola isodon, Нгок Линь, Вьетнам, первая находка.

\section{Introduction}

Harpiola which was treated as subgenus of Murina (e.g. Koopman, 1994) or full genus (Thomas, 1915; Tate, 1941), for long time was known only by single specimen from India, assigned to the species Harpiola (or Murina) grisea Peters, 1872. In the last years one more specimen of this species was captured in India (Bhattacharyya, 2002). The series of specimens collected on Taiwan was used as a type material for the new species, H. isodon Kuo et al., 2006, which distinguish from $H$. grisea by certain dental features (Kuo et $a l ., 2006)$. Thus the whole number of known specimens of the Harpiola was raised up to thirteen, and all known localities were restricted to India and island of Taiwan (Kuo et al., 2006).

In March-April 2006, the Russian-Vietnamese Tropical Centre conducted an intensive biodiversity survey in Ngoc Linh Mts (Central Vietnam). Ngoc Linh Mountains, lying on the border of Quang Nam and Kon Tum provinces) is located in Vietnam's Western Highlands. The area is at high elevation, with Mount Ngoc Linh, Vietnam's second highest peak at $2598 \mathrm{~m}$, as its most prominent feature. During this expedition the mist net setting for ornithological studies occasionally captured the single small tube-nosed bat specimen. After the examination of the specimen in Zoological Museum of Moscow State University, the whole complex of specific Harpiola features was revealed. Moreover the mentioned specimen greatly corresponds to the description of $H$. isodon, and thus representing the first record of the species Vietnam and the first record out of Taiwan.

\section{Materials and methods}

A subadult or young adult male of the tube-nosed bat was collected on 28 March 2006 from Ngoc Linh Mt. (N 1504'46", E 107 58'28'), Kon Tum Province, Vietnam, at an altitude of about 2250 meters above sea level. The specimen is housed in the collection of the Zoological Museum of Moscow State University, ZMMU S-180001.

The bat was captured by nylon mist net $(10 \times 2.5 \mathrm{~m})$, which was set for ornithological researches. The captured bat was preserved in $70 \%$ ethanol, and then in the laboratory conditions the skull was extracted for measuring. The following 11 cranial measurements were taken with the accuracy of $0.01 \mathrm{~mm}$ using digital caliper in combination with a binocular microscope: total length, condylobasal length, condylocanine length, mastoid 


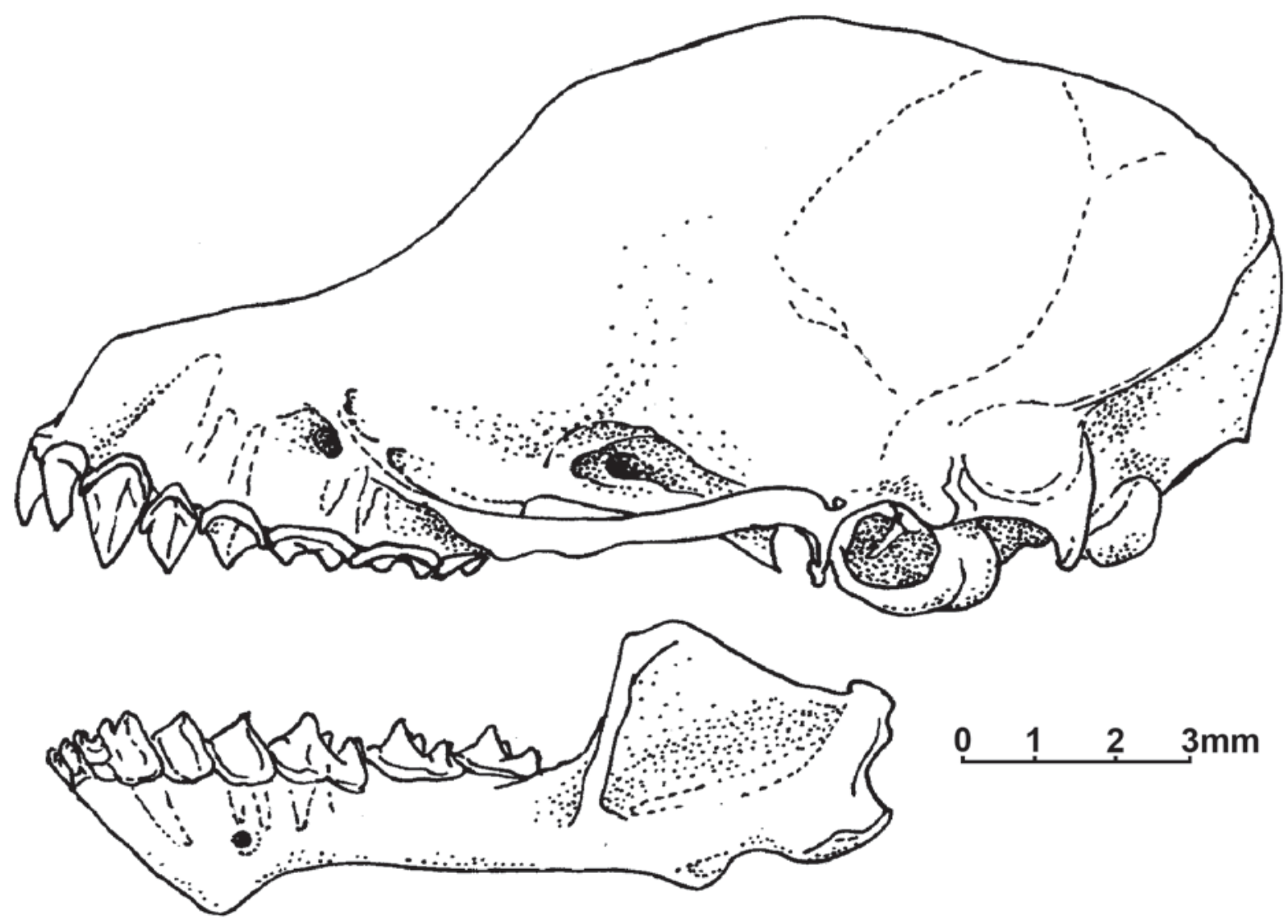

Figure 1. Skull and lower jaw of Harpiola cf. isodon (ZMMU S-180001) from Ngoc Linh, Vietnam in lateral view. Scale bar is $3 \mathrm{~mm}$.

width, width across postorbital constriction, greatest zygomatic width, crown length of the upper tooth row from $\mathrm{C}$ to $\mathrm{M} 3$, width across outer margins of upper canines, width across outer margins of M3, crown length of maxillary tooth row, mandible length from alveolus of il to the articulated process. Standard external measurements, including head and body length, tail length, forearm length, ear length and tragus length were taken to the nearest $0.1 \mathrm{~mm}$.

\section{Results}

Identification and description. Captured specimen represents a small tube-nosed bat: head and body length is $42.5 \mathrm{~mm}$, tail length is $28 \mathrm{~mm}$, and forearm length is $31.7 \mathrm{~mm}$. In general appearance it well corresponds with description of Harpiola isodon, being slightly smaller than recent Indian specimen of $H$. grisea (see Bhattacharyya, 2002) and having dark-brown underfur and guard hairs tipped with bright gold. As in $\mathrm{H}$. isodon, last caudal vertebra is free from tail membrane. Tail membrane is covered with thick hairs right to the margin. Orange-golden hairs also cover the whole upper sides of the forearms, basal half of thumbs and basal thirds of fifth metacarpals. Tragus is tapering to the tip, which is slightly curved backward, almost reaching the ear notch.

Skull looks having more pronounces frontal depression (in lateral view) than it was shown for $H$. isodon (Fig. 1). The Ngoc Linh specimen almost corresponds $H$. isodon in all cranial measurements being meantime slightly smaller then $H$. grisea, except to width across upper canines; postorbital width and mandible length (Tab. 1). Noteworthy that first two of these measurements look proportionally larger in $H$. isodon with respect to $H$. grisea. Lower jaw of Ngoc Linh specimen has long inclined symphysis and specific lobe anterior to angular process, which is known to both Harpiola species.

Dentition is very characteristic. The Ngoc Linh specimen can be easily determined as Harpiola by its upper canine and two premolars equal in crown area and gradual decrease in height of these teeth from $\mathrm{C}$ to $\mathrm{P} 4$ (Fig. 1). Lower canine is distinctly bicuspid (Fig. 2A). Posterior upper premolar is wider than long; third upper molar possess well-defined postcingular shelf; on both first and second upper molars weak trace of mesostyle can be seen. All these features associate the Ngoc Linh specimen with $H$. isodon.

The one else thing concerning dentition need to be elucidate. Lower molars of tube-nosed bats are quite 
Table 1. Selected external and cranial measurements (in $\mathrm{mm}$ ) of Ngoc Linh specimen and two species of Harpiola.

\begin{tabular}{|c|c|c|c|}
\hline Measurements & $\begin{array}{c}\text { H. grisea, India } \\
\text { (Bhattacharyya, 2002) }\end{array}$ & $\begin{array}{l}\text { H. cf. isodon, } \\
\text { Ngoc Linh, Vietnam } \\
\text { (ZMMU S-180001) }\end{array}$ & $\begin{array}{c}\text { H. isodon, } \\
\text { Taiwan, } \mathrm{n}=11 \\
\text { (Kuo et al., 2005) }\end{array}$ \\
\hline Forearm length & 32.4 & 31.7 & $31.00-35.60$ \\
\hline Ear length & 12.1 & 11.8 & $12.5-13.0$ \\
\hline Tragus length & 6.0 & 6.5 & $6.5-8.0$ \\
\hline Total length of skull & 16.4 & 15.41 & $14.76-16.48$ \\
\hline Condylobasal length & - & 14.49 & $13.74-14.87$ \\
\hline Condylocanine length & 14.8 & 13.75 & - \\
\hline Width across outer margins of upper canines & 3.7 & 3.98 & $3.65-4.02$ \\
\hline Width across outer margins of M3 & 5.5 & 5.32 & $4.90-5.53$ \\
\hline Crown length of the upper tooth row from $\mathrm{C}$ to $\mathrm{M} 3$ & 5.3 & 5.39 & $4.97-5.63$ \\
\hline Mastoid width & 8.0 & 7.68 & $7.29-7.96$ \\
\hline Width across postorbital constriction & 4.3 & 4.47 & $4.52-4.84$ \\
\hline Greatest zygomatic width & 9.4 & 8.94 & $8.43-9.35$ \\
\hline Crown length of maxillary tooth row & 5.7 & 5.68 & $5.35-5.90$ \\
\hline Mandible length from alveolus of i1 to the articulated process & 10.6 & 10.80 & $10.15-11.32$ \\
\hline
\end{tabular}

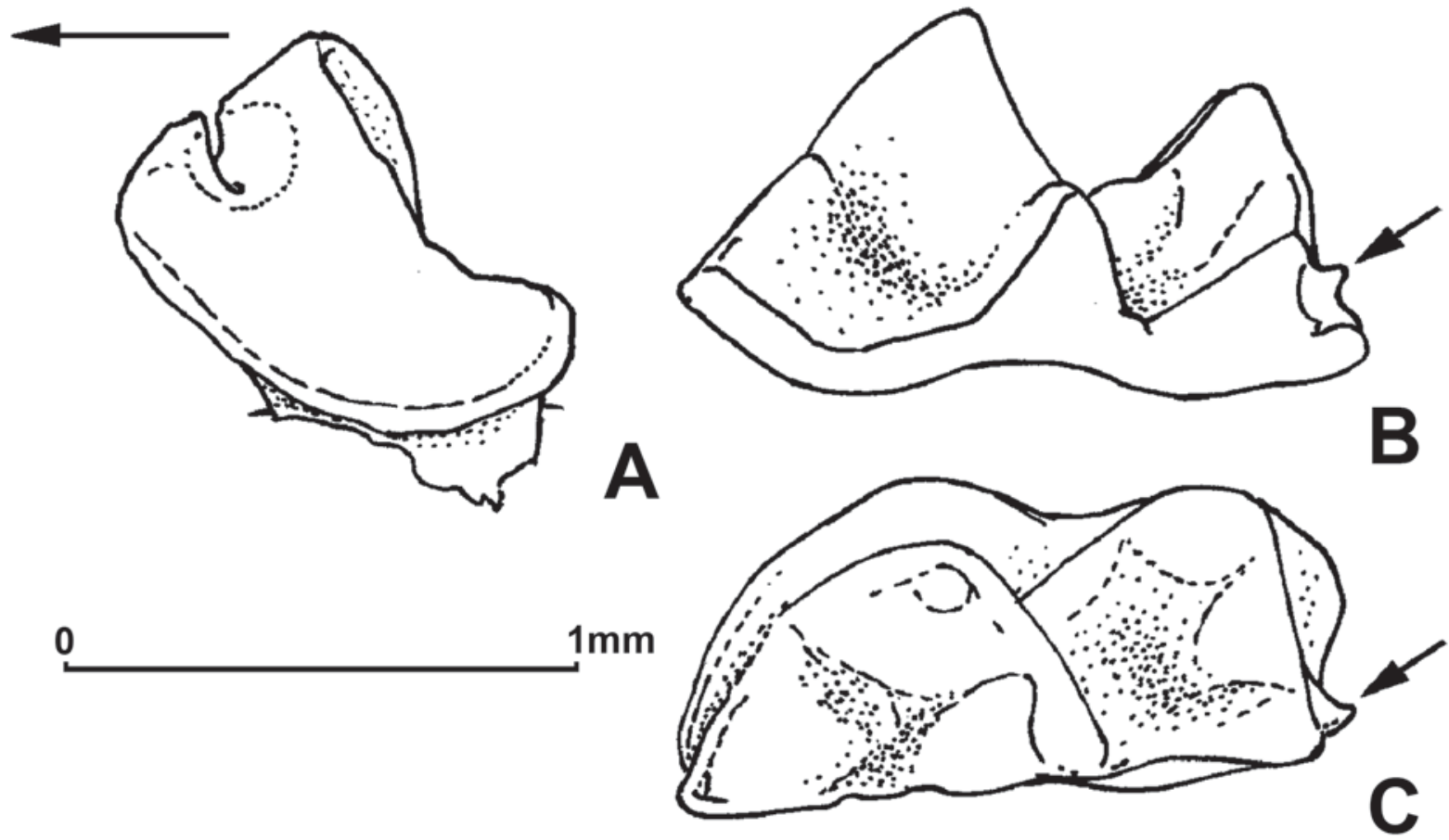

Figure 2. Selected dental features of Harpiola cf. isodon (ZMMU S-180001) from Ngoc Linh, Vietnam: bicuspidate lower canine, in lingual view (A) and the first lower molar (m1), demonstrating myotodont type of crown, in lingual (B) and occlusal (C) views. The arrow shows anterior direction (A), or points to the hypoconulid (B and C). Scale bar is $1 \mathrm{~mm}$.

specific in talonid morphology, and were usually interpreted as representing «nyctalodont» type. Entoconid and hypoconulid on Murina molars are strongly connected with special crista or even stand so close that it can be joint into solid somewhat elongated cusp. For such situation, seen in Murina hilgendorfi, M. ussuriensis, M. aurata, M. huttoni and some other species, the new term «murinodont» was suggested (Rossina, 2003). Usually, nevertheless, in the mentioned species postcristid is connected with rudimentary hypoconulid, which 
gives possibility to derive «murinodontia» from «nyctalodontia». Meantime, the Ngoc Linh specimen, by many features assigned to Harpiola, possess other type of lower molars - more or less typical «myotodont» (sensu Menu, 1985) (Fig. 2B, C). The postcristid is definitely connected with entoconid, while hypoconulid is weak but well seen and not merged with entoconid by special crista.

Ecological notes. The animal was captured into mist net setting across ravine with small stream, at the elevation of 2250 meters a.s.1. (which fact corresponds with known ecology of Harpiola from Taiwan), in the evening (approximately at 18.00). It was caught into side pocket of the net, about four meters above the ravine bottom. Surroundings of the capture place are covered with mountainous deciduous moss forest with admixture of pine trees and with numerous small streams; few rock outcrops are situated only on somewhat lower elevations, 1800 to 2100 meters a.s.l. Some other bats were observed in the same place, but neither identified nor captured.

ACKNOWLEDGMENTS. We are grateful to Dr. A.N. Kuznetsov and Dr. Phan Luong for their enormous efforts for the organizing of the expedition. Some comparative material on Murina species was processed by S. Kruskop during his visit to Geneva Museum of Natural History, organized by Dr. Manuel Ruedi. Zoological Museum of Moscow State University represented all other comparative material.

\section{References}

Bhattacharyya T.P. 2002. Taxonomic status of the genus Harpiola Thomas, 1915 (Mammalia: Chiroptera: Vespertilionidae), with a report of the occurrence of Harpiola grisea (Peters, 1872) in Mizoram, India // Proceedings of the Zoological Society, Calcutta. Vol.55. P.73-76.

Koopman K.F. 1994. Chiroptera: Systematics. Handbook of Zoology. Mammalia, Part 60. Berlin: Walter de Gruyter. $217 \mathrm{p}$.

Kuo Hao-Chi, Yin-Ping Fang, Csorba G. \& Ling-Ling Lee. 2006. The definition of Harpiola (Vespertilionidae: Murininae) and the description of a new species from Taiwan // Acta Chiropterologica. Vol.8. No.1. P.11-19.

Menu H. 1985. Morphotypes dentaires actuels et fossils des Chiroptères Vespertilioninés. I Partie: Étude des morphologies dentaires // Palaeovertebrata. Vol.15. No.2. P.71-127.

Rossina V.V. 2003. Murinodontia - the special type of morphology of bat lower molar crowns // Plecotus et al. Vol.6. P.3-6.

Tate G.H.H. 1941. Results of the Archbold expeditions no. 40. Notes on Vespertilionid bats of the subfamilies Miniopterinae, Murininae, Kerivoulinae and Nyctophilinae // Bulletin of the American Museum of Natural History. Vol.78. P.567-597.

Thomas O. 1915. A special genus for the Himalayan bat known as Murina grisea // Annals and Magazines of Natural History. Series 8. Vol.16. No.94. P.309-310. 